\title{
A trial to convert a polymer FDM 3D printer to handle clay materials
}

\author{
Mohamed Zied Chaari $^{1}{ }^{10} \cdot$ Mohamed Abdelfatah $^{1} \cdot$ Christopher Loreno $^{1}$
}

Received: 21 October 2021 / Accepted: 4 January 2022

Published online: 04 February 2022

(c) The Author(s) 2022 OPEN

\begin{abstract}
The research aims to show the ability to convert the Fused Deposition Modeling 3D printer to be compatible with the clay mixture after modifying the structure, setting up Cura software, and changing the print head technology. This solution provides research teams and scientists with opportunities in several ways (manufacture patch antenna substrate, dielectric automobile sensors, and ceramic dielectric aerospace technology). Additive manufacturing allows the production of many intricate shapes with ceramics, which is difficult with a traditional method. This paper used WASP ceramic slurry as raw material for Liquid Deposition Modeling (LDM) of various samples using the Archimedes screw and air pressure dispensing technique (a two-step process). LDM is a low-cost and straightforward technology appropriate for the clay prototype scale. Different clay-built shapes have been produced with water-to-clay ratios ranging from 0.57 to 0.69 . The effect of the nozzle size in printing experiment tests is demonstrated. The experiment tested the print head (extruder) mechanism, the properties of the materials suitable for the putty, and how the wet slurry material is extruded from the nozzle. The optimum air pressure and slicing configuration for efficient printing are provided. Samples were stress-tested after they were dried for $24 \mathrm{~h}$ at average laboratory temperature and then exposed to $1000^{\circ}$ for $1 \mathrm{~h}$.
\end{abstract}

Keywords 3D printing - Dispensing system - Clay materials - Ceramic product

\section{Introduction}

Many dielectric products are made from ceramic clay (medical sensors, vehicle sensors, engineering devices, and radiofrequency devices) and produced by specialized technologies. There are many concerns to consider in designing a ceramic product, such as form, surface decoration, and materials. Forming is the foundation of ceramic product design and is also a critical method for manufacturing [1, 2]. The main forming processes are traditionally handcrafted forming, molding, and 3D printing [3-5]. In this method, workers depend on experience and aesthetic perception to make the clay shape by the handthrowing technique and forming with a plaster mold.
In another method, a plaster mold is usef to make the clay model. Ceramic artists use the slip casting technique with a plaster mold and form a thin-walled body of the ceramic product. Sometimes, they press small parts of the ceramic product into the body in the plaster mold with their hand. A 3D printed product from a computer-aided design (CAD) has higher precision than a handmade ceramic article. The 3D printer has an extruder whose position is controlled precisely by an embedded system. This system can handle the quantities of clay extruded and the extrusion time. Moreover, the high-density ceramic slip is the best material for indirect 3D printing of a product.

3D printing clay is a new effective additive manufacturing (AM) technique that has emerged as a technology

Mohamed Abdelfatah and Christopher Loreno have contributed equally to this work.

Mohamed Zied Chaari, chaari_zied@ieee.org; Mohamed Abdelfatah, mohamed.abdelfatah@qsc.org.qa| ${ }^{1}$ Fabrication Laboratory, QSC, Wholesale Market, Doha 9769, Qatar. 
for manufacturing shapes with complex geometries from three-dimensional (3D) model data [6,7]. During the 3D printing method, adhesive materials or metal powder with a polymer shrinkage characteristic is used in the $3 \mathrm{D}$ printer $[8,9]$. Layer-by-layer printing is the principal method to perform additive manufacturing $[10,11]$. 3D clay printing is similar to polymer 3D printing without needing a "hot tip" on the extruder [12]. The clay 3D printer compresses the clay paste and deposits it in layers according to the $\mathrm{G}$-code instructions. The result is a 3D structure of clay that can be heated and hardened, just like a handcrafted piece of clay. The new clay additive manufacturing technique has been extensively used in many product designs, such as the dielectric ceramic antenna or sensors. In 2014, WASP, the Italian 3D printer manufacturer, produced a new kind of Delta-type 3D printer with an extruder with more freedom [13]. In 2016, Zhang and Ling described two ceramic forming methods based on 3D printing solution [14]. In 2020, Emmanuel et al. studied additive manufacturing solid microfluidics via silver vlay extrusion [15]. In 2020, Ruscitti and his team reviewed additive manufacturing of ceramic materials based on extrusion processes of clay pastes [16].

In 2019, the University of Delaware installed the XJet Carmel 1400 ceramic 3D printer, with the aim of overcoming the $5 \mathrm{G}$ network hurdles with 3D printed ceramic antennas [17]. In 2019, Rarani et al. studied the possibility of modifying a fused deposition modeling (FDM) 3D printer to print continuous carbon fiber-reinforced PLA composites [18]. In 2020, Anywaves and 3DCeram collaborated on an aerospace project. They have developed a 3D printed ceramic low-profile GNSS antenna using AM with substantial ceramic materials [19]. In fact, 3D printing of ceramic components is more rapid and efficient than traditional forms, with a lower manufacturing cost for ceramic shapes. A prototype sample of a 3D clay printer is developed and utilized to verify its efficiency before use to create high-precision shapes or make patch antenna substrates [20-22]. The procedures of 3D printing with ceramics [23-25] are shown in Fig. 1. This work converts a polymer FDM 3D printer to a ceramic 3D printer for a prototyping scale with a dedicated extruder to control the flow of the material slip. This technique differs from other ceramic 3D printers that use powders or other materials. It is simple, cheaper, and easy to make in a lab. We can use it to fabricate dielectrics for sensors, antenna, and other components with high efficiency without purchasing an expensive and complicated 3D printer clay. The conductivity and thermal conductivity of 3D printed ceramic dielectrics depend on the physical properties of the clay material.

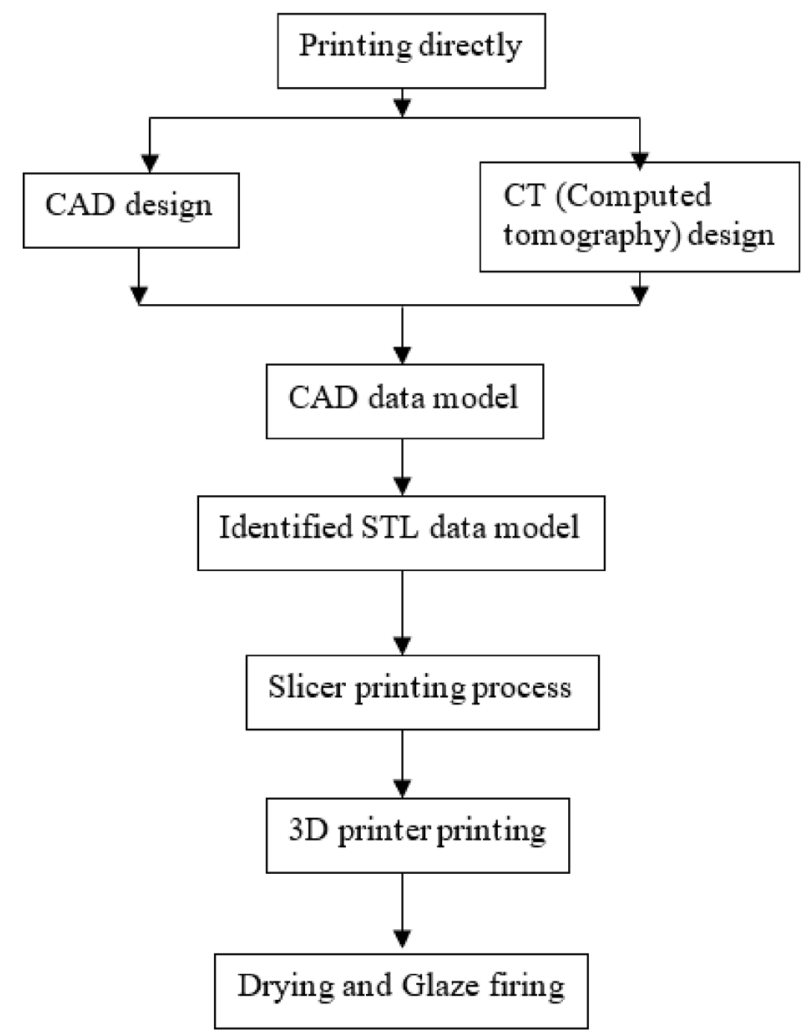

Fig. 1 Flowchart of the 3D process of ceramic manufacture by slip

Table 1 Chemical composition of the WASP raw clay

\begin{tabular}{ll}
\hline Major elements & $\begin{array}{l}\text { Compo- } \\
\text { sition } \\
\text { (wt\%) }\end{array}$ \\
\hline $\mathrm{Ca}$ & 77.97 \\
$\mathrm{Si}$ & 11.46 \\
$\mathrm{Al}$ & 1.98 \\
$\mathrm{~K}$ & 0.85 \\
$\mathrm{Fe}$ & 7.74 \\
\hline
\end{tabular}

\section{Materials and methods}

Therefore, this work purpose concentrates on the development of a 3D clay printer with two main targets:

- Material properties of 3D clay printed shape

- Dispensing mechanism for 3D printer (air pressure, printing speed, and travel speed) 


\subsection{Materials}

SWAP SA supplied the earthenware clay mixture. Its chemical composition is summarized in Table 1. The earthenware clay is used for all experiments, and only the amount of water was varied [26, 27]. Therefore, the composition was expected to have little or no effect on the final printed parts as they would be subjected to a printing process.

A converted solution is a simple and inexpensive technology suitable for adaptation for lab prototyping. Different shapes made from clay were manufactured with a water-to-clay ratio (W/C) of between 0.57 and 0.69 , as shown in Table 2. Clay is an incredibly challenging material to work with because it must have the right viscosity for printing, ensuring that it is neither too thin or viscous before use.

The clay is cut into thin strips using a wire and then dipped into water to be hydrated before being loaded into an aluminum container, as shown in Fig. 2.

\subsection{Dispensing system}

The dispensing mechanism is essential for a modified liquid deposition modeling (LDM) 3D printer to deliver a sufficient and consistent amount of paste. We test two different typologies of dispensing paste, one with a single step (Archimedes' screw) and another with two steps (pneumatic piston and Archimedes' screw) [28], as shown in Fig. 3:
- Single-step methods comprise a cylinder or sleeve where the clay or paste is previously loaded and a piston that pushes it to run through an orifice. The piston can be used in two ways:

1. Mechanic extruder by the linear strength of a motorized screw and nut mechanism

2. Pneumatic piston, with compressed air, such as linear actuators; the air pump feeding type to extruding clay materials and the dispensing system

- Two-step methods use the pneumatic or mechanical plunger to solve the feeding of clay through a tube to the second stage, where the extrusion occurs. This last step can be solved using a motorized mechanism of two types:

1. Archimedes' screw, in a cylindrical shaft, such as that of the extruders of the ceramic

2. Endless plunger, consisting of a simple helical metal rotor

We optimize the dispenser mechanism to control the extrusion according to materials' relevant properties, such as filling materials and compressive strength.

After testing both methods, the pneumatic plunger with Archimedes' screw extruder provided better flow material and continuous extrusion of wet clay. Simultaneously, it was hard to control the materials' layering only air pressure (single step). Therefore, this study uses a two-step dispenser system: the screw feeder with air pressure to push and dispense the clay material. The air pump pushes
Table 2 Effective water/clay ratio

Fig. 2 Preparation and loaded clay into a container

\begin{tabular}{lllllll}
\hline Clay $(\mathrm{g})$ & 60 & 60 & 60 & 60 & 60 & 60 \\
Water (g) & 34.2 & 35.4 & 36 & 36.6 & 37.8 & 39 \\
Clay (wt\%) & 63.7 & 62.9 & 62.5 & 62.1 & 61.3 & 60.6 \\
Water (wt\%) & 36.3 & 37.1 & 37.5 & 37.9 & 38.7 & 39.4 \\
W/C ratio & 0.57 & 0.59 & 0.6 & 0.63 & 0.65 & 0.69 \\
\hline
\end{tabular}
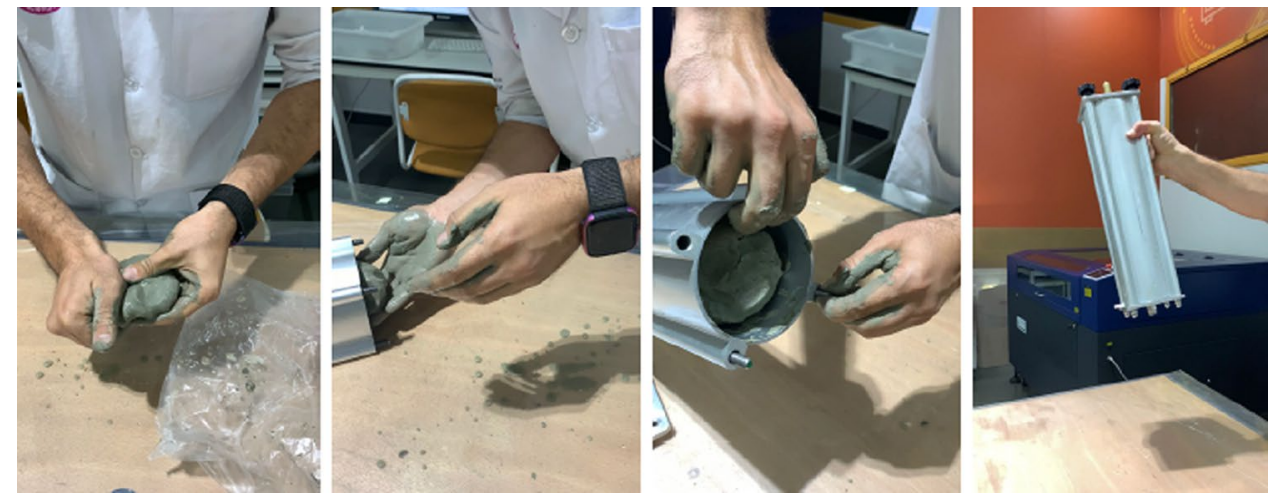

SN Applied Sciences A SPRINGER NATURE journal 
Fig. 3 Classification of dispensing devices

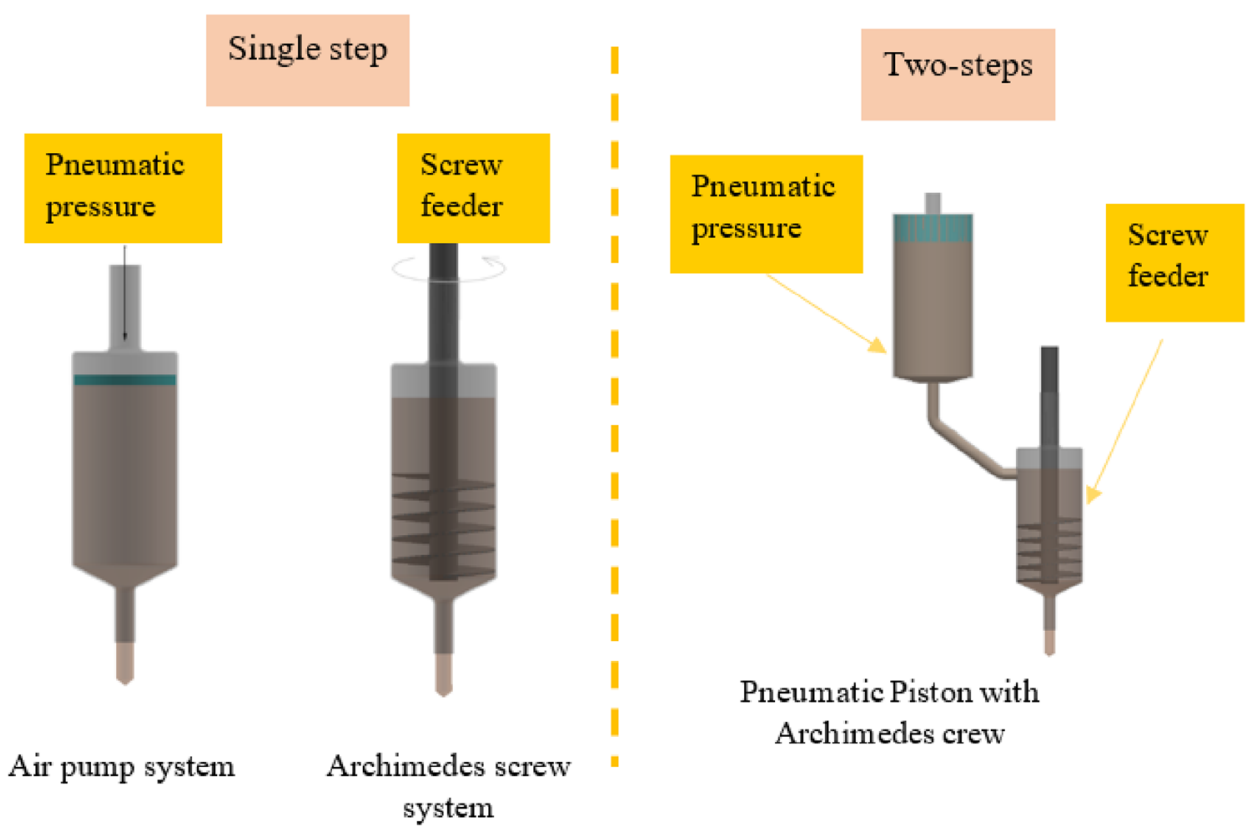

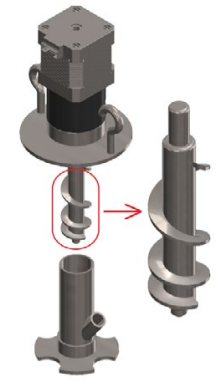

(a) 3D exploded parts

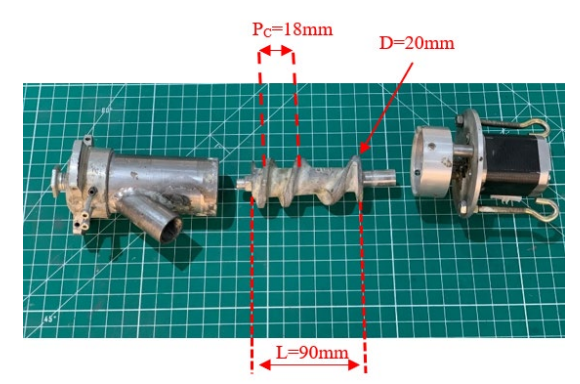

(b) Screw feeder exploded parts
Fig. 4 Lab-made print head extruder

the clay placed into the aluminum container to provide materials to the print head with high streamlining. The air pressure control valve keeps the piston under force against the clay in the container. This technique keeps materials flowing to the extruder without air bubbles with low printing speed and guarantees good material flow.

\subsubsection{Screw print head}

We made a new clay-delivery screw extruder that is mechanically attached to the 3D print head body [29]. The new screw feeder ensures that the clay glides smoothly during the printing process. The screw feeder is connected by three connecting rods, and it can print with ceramic slip directly. The nozzle or orifice decides the dimension of the extruded line of clay [30,31]. The screw is coupled to the stepper motor (NEMA17) and operates inside the extruder, as shown in Fig. 4a. A stepper motor drives the conveyor screw, which forces the clay to the slip. The orifice size decides the dimension of the extruded line of ceramic. In this study, we prepare three different sizes of the orifice (1 $\mathrm{mm}, 1.6 \mathrm{~mm}$, and $3 \mathrm{~mm}$ ).

The specifications of the designed screw are as follows: the pitch of the screw (Pc), $18 \mathrm{~mm}$; diameter (D), $20 \mathrm{~mm}$; the total length of the screw $(\mathrm{L}), 90 \mathrm{~mm}$; the angle of the blades, around $19^{\circ}$, as shown in Fig. 4b [32]. Moreover, we design a screw with different pitch ratios to diameter (Pc/D). A screw with a rate of around 0.9 yielded extrusion with enough pressure to squeeze out the clay. This factor is related to the accuracy of screw rotation speed and slurry extrusion quantity by adjusting the quantity to build a consistent layer.

\subsubsection{Slicing}

The slicing step is a critical method during the LDM printing process [16, 33-35]. There are different G-code algorithms for choosing extruder routes. There is a dynamic balance between the materials used, printing speeds, and printing quality factors. The print path is first created by the G-code file; after creating the G-code file, the print preparation phase for printing is initiated. We modify the Cura software parameters to be compatible with our 3D ceramic application and adaptable with the orifice. We use Cura slicer software to convert CAD files into G-code as parameters (layer height, shell thickness, fill density, print speed, support, travel speed, orifice size, etc.). Before slicing, we need to consider the nozzle's size and the corresponding layer height. If layers are too high to the size 
of the nozzle, the clay will not join together. While layers that are too small can result in overextrusion, pushing too much clay atop each other can cause clogging or ruin prints. The modified printing parameters of the Cura software are as follows:

- Layer height = slice height (between 1 and $3 \mathrm{~mm}$ depending on the scale of print, which also influences the choice of nozzle size).

- Shell thickness $=1$. In other words, the "shell thickness" is calculated by dividing the thickness by the given nozzle thickness.

- Enable retraction $=$ do not thickness.

- Fill bottom/top thickness $=0$ (we print onto a prepared slab of clay for a base). Usually, printed bases have a habit of cracking later during the drying phase.

- Fill density $=0$.

- Print speed $=28 \mathrm{~mm} / \mathrm{s}$, which a good starting point.

- Print temperature $=0$ (3D printing without needing a "hot tip").

- Support = we have not got involved with support, so none.

- Filament $=$ this is irrelevant as we manually control the clay flow with the air pressure.

- Nozzle size $=1$ for simplicity for now .

- Retraction = irrelevant

- Initial layer thickness = this can be set smaller than your slice layer to get an excellent first layer contact.

- Initial layer line width $=100 \%$.

- Cut-off =0.

- Dual extrusion = irrelevant

- Travel speed $=80 \mathrm{~mm} / \mathrm{s}$.

- $\mathrm{Cool}=$ irrelevant.

\subsection{Methods}

In this study, the objective is to convert plastic printers to ceramic printers to be available for individual users and researchers who are conducting the prototyping. Thus, we will observe how 3D ceramic printers affect the production skills of individual users such as artists, designers, and scientists. FDM is usually done by depositing layers in a computer-controlled manner from the plastic loaded to the printer in the form of a filament fused upon reaching the extruder [36]. The same would be done with ceramics. The 3D ceramic printer has two essential differences from polymer printers: an appropriate extruder is used for printing cold production and the extruder works by dissolving. A second air compressor is necessary to push the material to flow back into cold production. It is required in order to move the material inside the print head by air pressure. Recently, researchers have been interested in combining 3D printing and ceramics to fabricate antennas, sensors, and other technologies. Desktop 3D printing is mainly attractive because it demands less space and equipment than a typical clay studio. Using a 3D printer with a custom screw extruder, we can print small and medium ceramic shapes with a width and height of $100 \mathrm{~mm}$.

The general concept design for 3D printer ceramic after the upgrade is shown in Fig. 5.

\section{Experimental results}

We use a FDM 3D printer to build the ceramic 3D shapes after converting them to a LDM printer, as shown in Fig. 6. The software (Cura 15.04.4) generates G-code from CAD files and controls printing with a printer motor control to drive three-axis motors. A converted $3 \mathrm{D}$ printer uses the dispensing system, a two-step method, and combines the air pressure with a screw feeder to increase the efficiency of the dispensing system. The printing capability and functionality are tested for clay models, concentrating on dispensing, layering, and size of the orifice.

This test's essential parameters are used to determine the material specification and building stability by examining the layering condition of clay materials, the proper mixture of materials, and their hardening method. In the tests, clay is mixed with water to find the best combination of the W/C ratio. Moreover, the effective viscosity is

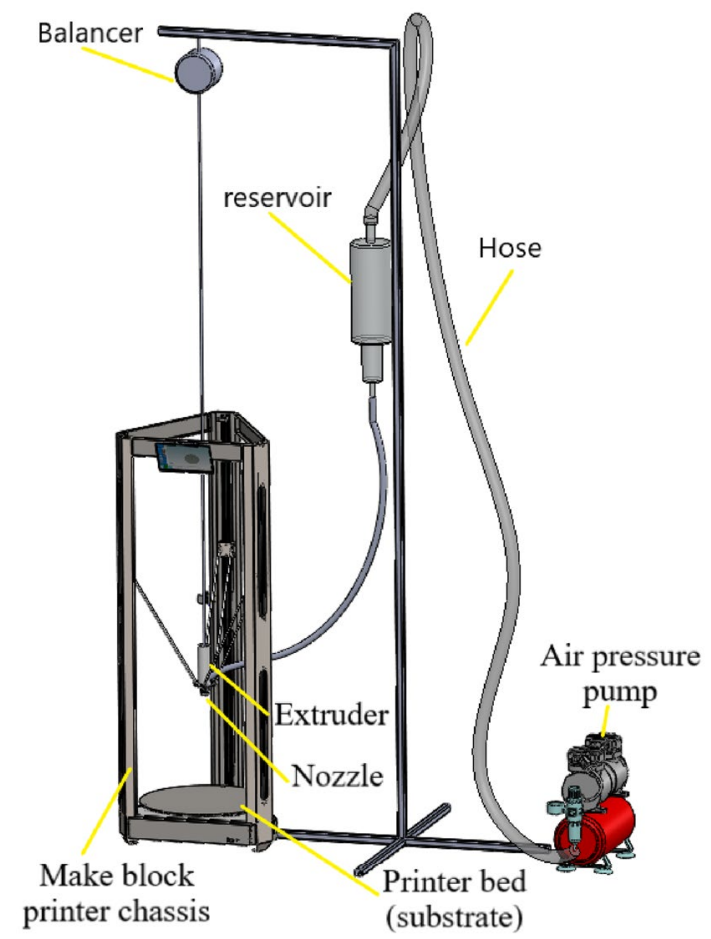

Fig. 5 Primitive concept design for 3D printer ceramic after conversion 


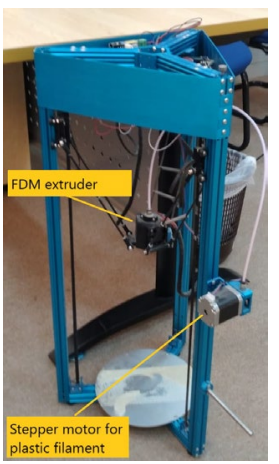

(a) Before modifying the Makeblock mGiraffe 3D printer to a $3 \mathrm{D}$ ceramic printer

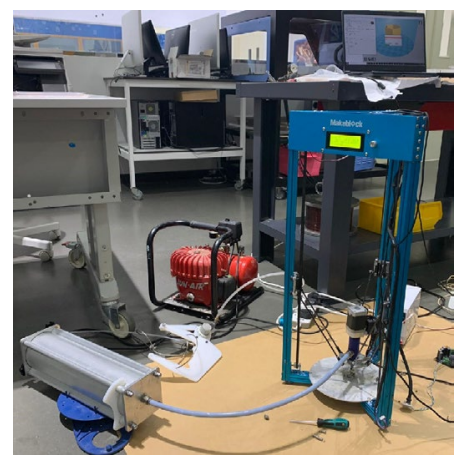

(b) Converting the FDM $3 \mathrm{D}$ printer to a LDM printer with a WASP print head
Fig. 6 Converting a polymer FDM 3D printer to handle ceramic materials

determined for the dispensing and layering of the materials. Therefore, the printer's appropriate mix design ratio is determined from the experiments' results.

\subsection{First experimental tests}

The results are presented in Fig. 7 and show a complex relationship between the orifice diameters and flow. Figure 7a shows the variation in volumetric and mass flow for different orifice diameters, while the printing time remains constant for all samples shapes. The evolution of sample height is shown in Fig. 7b. As expected, as the orifice diameter increased, flow and height also increased during the same printing time. Flow data show that the flow was relatively constant for small orifice diameters ( 1.0 and $1.6 \mathrm{~mm}$ ). However, when the orifice diameter was large (3 $\mathrm{mm})$, the flow decreased with time. This could be related to the 3D printer controlling the speed of the slurry emanated from the orifice rather than directly controlling the flow. The flow tests for a W/C of 0.60 show that the crawl, yield strength, and recovery compliance helped select the best 3D printing formulation material. A W/C of 0.60 is not high enough in water content to make the sample fluid and thus unstable when printed or low enough in water content to make the flow through the orifice almost impossible. In the following experiments, the W/C of 0.65 is applied.

During the tests, the print head orifice diameter was $3 \mathrm{~mm}$, and the plat size is related to the full range of the printer head movement on each axis. Before printing any shape with different blending materials, we ran an experiment on clay with a 3D printer to create print settings, such as the speed of extruder movement, the rate of rotation of the Archimedean screw, and the height of the extruder. At this stage, we are not worried about the effect of the substrate on $3 \mathrm{D}$ printing; we will use aluminum substrate. The goal here is to print a ceramic cup with a diameter of about $40 \mathrm{~mm}$ and a height of $70 \mathrm{~mm}$ that the slurry extrusion printer should produce. Initially, the stagnant flow diffusion value is determined using clay paste. This step is necessary for the distribution and layering of clay materials. Hence, the viscosity of the material is essential for precise distribution and layering. A slump flow tester is used to create the acceptable mixture of slurry before printing begins.

\subsection{Second experimental tests}

In this test, we use the laboratory-made extrusion print head while maintaining a nozzle diameter of $3 \mathrm{~mm}$. We printed several 3D shapes using the lab-made print head, but not all printed shapes are acceptable. All 3D printed shapes fail, as shown in Fig. 8a, b. The first mixture was not acceptable due to the unfair distribution. The layers are misaligned and shifted relative to each other, and there were also small points on the surface, known as zits, as shown in Fig. 8c. Layer shifting is one of the clearest failures because it affects the visual appearance and dimensional accuracy. Simply put, layer shifting is where layers unintentionally and continuously move as the shape is being printed. This is because the lab-made print head has a mechanical balancing problem. In the following tests, we will use the WASP extruder 3.0, while maintaining the nozzle diameter of $3 \mathrm{~mm}$ and reducing the printing speed.

We changed Cura to reduce the print speed parameter to improve the printed look at this phase. Moreover, we keep the air pressure despite modifying the layer shifting.

\subsection{Third experimental tests}

We decided to change the lab-made print head for the WASP extruder 3.0 to provide the ceramic slip directly. To install the WASP print head to the FDM printer chassis, we designed and manufactured a mechanical support adapter to improve the printer with the head length specified. The extruder connects to three connecting rods. The ceramic slip directly through the air-compressed cylinder keeps material sliding without air bubbles into the print head. These exploratory tests showed that the clay material did not extract very well. The printed shape with slump clay leaves the orifice. The printer extrudes too much clay, as shown in Fig. 9. To reduce this effect, we adjusted several times the tank's air pressure until we reached the optimum air pressure. We succeeded after several experiments to find the optimum air pressure ( $86 \mathrm{PSI}$ ). The slip consistency/viscosity parameters have yet to be optimized. 
Fig. 7 All for the sample formulation $\mathrm{W} / \mathrm{C}$ of 0.60

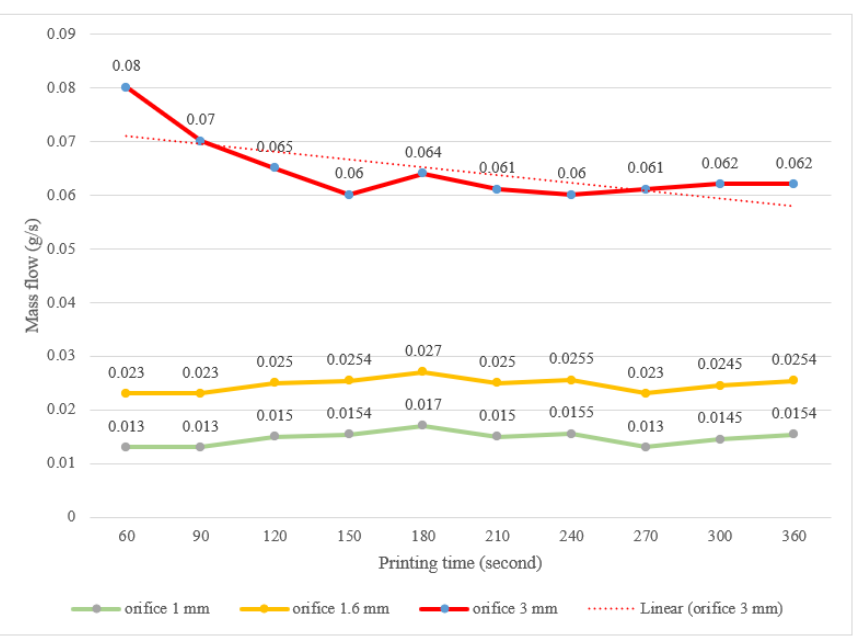

(a) Mass flow $(\mathrm{g} / \mathrm{s})$ as a function of the printing time for different nozzle diameters

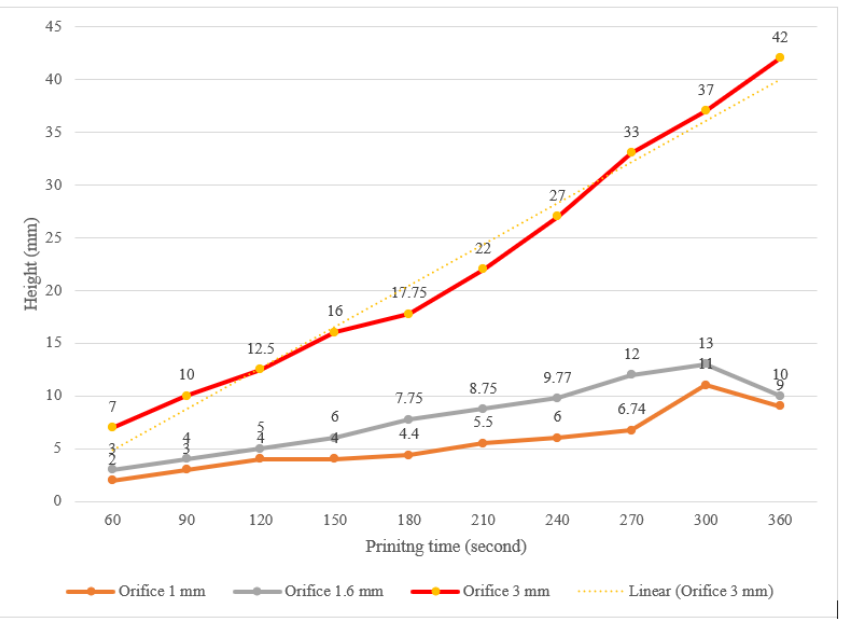

(b) Height of samples as a function of the printing time for different nozzle diameters

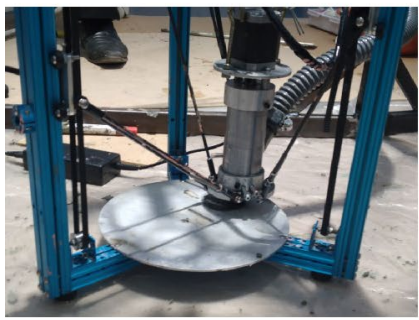

(a) First test (air pressure $90 \mathrm{PSI}$ and printing speed $28 \mathrm{~mm} / \mathrm{s}$ )

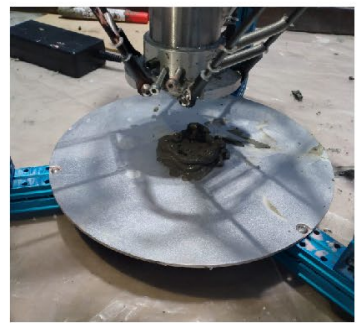

(b) Second test after adjusting the slicing parameters (printing speed $26 \mathrm{~mm} / \mathrm{s}$ )

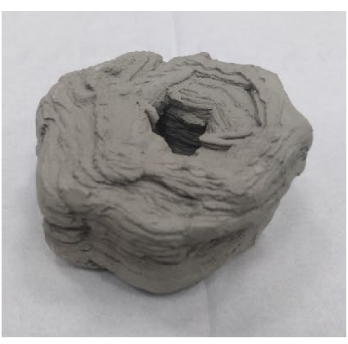

(c) Layer shifting 

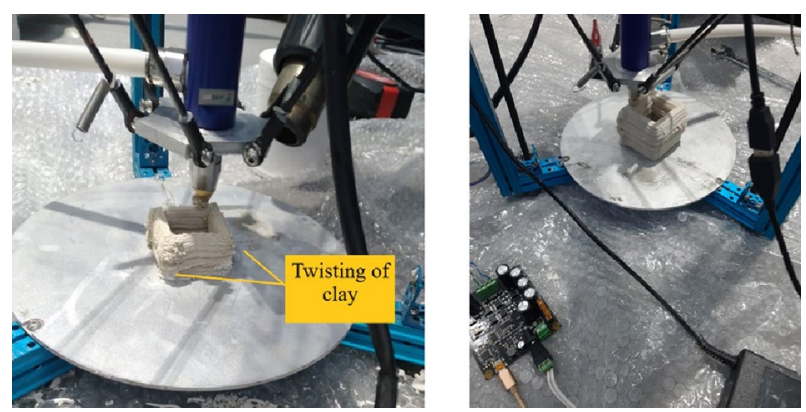

Fig. 9 Overextrusion

\subsection{Fourth experimental tests}

We maintain the air pressure to move the clay to the print head with high streamlining (86 PSI). Other printing parameters can be changed to reduce the effect of sludge in the previous test. We modified the print parameters for Cura as follows:

- Print speed $=24 \mathrm{~mm} / \mathrm{s}$.

- Travel speed $=76 \mathrm{~mm} / \mathrm{s}$.

Fig. 10 The cylindrical cup made by direct 3D printing (without slump clay leaving the orifice)

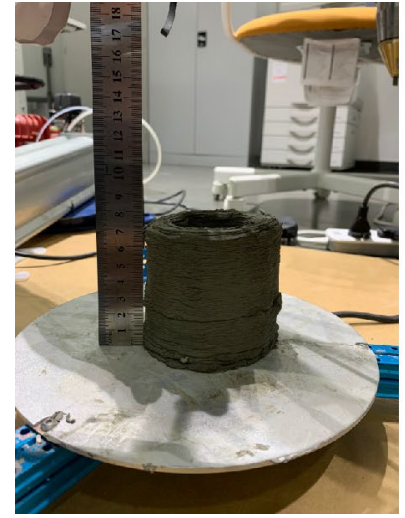

(a) Cup higher than 70 $\mathrm{mm}$

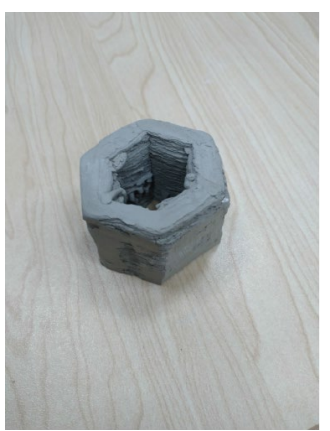

(a) Pentagon shape

According to the update value, we succeeded to find the optimum slicing configuration for efficient printing. After all adjustments, we made a 3D ceramic cup with a diameter of $40 \mathrm{~mm}$, height of $70 \mathrm{~mm}$, and wall thickness of $12 \mathrm{~mm}$, as shown in Fig. 10. The printing process takes about 123 min to print a cylindrical cup wall consisting of 288 layers. These experimental tests showed that the clay material is good for extraction, distribution, and layering, suitable for 3D printing.

The extruder functions very well, but it is very slow. One means of increasing the rate is to change the stepper motor. The motor presently being used is a typical $1.6 \%$ step. To multiply the extruder speed by a factor of two, we change the stepper motor for a lower resolution, higher speed stepper motor $\left(3.2^{\circ} /\right.$ step). Print speed can cause a 3D printing layer to shift. Figure 11 shows 3D samples fabricated based on the modified FDM printer and earthenware clay mixture, with the optimum air pressure, recent printing parameters of the Cura software, and higher speed stepper motor. Several printed parts illustrating the characteristics of the method and device used in this research are presented in Fig. 11a-c, respectively.

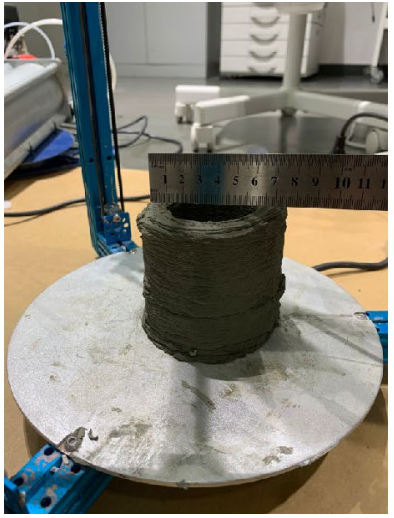

(b) Cup diameter of 70 $\mathrm{mm}$ (inside diameter $=$ $46 \mathrm{~mm})$

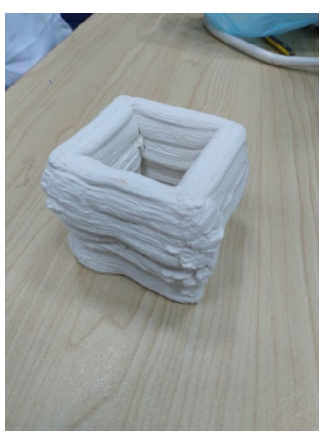

(b) Rectangular shape

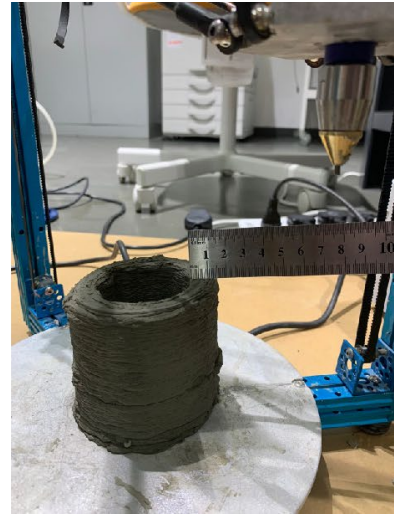

(c) Cup well thickness = $12 \mathrm{~mm}$

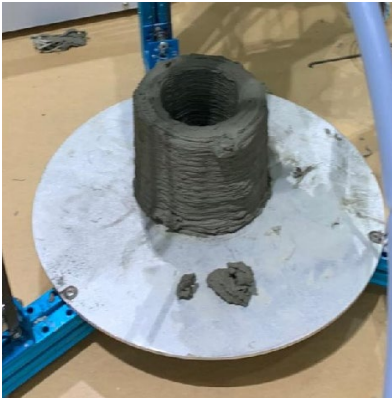

(c) Circular shape 
During the printing phase, manual drying is applied with a heat gun to keep the printed shape more robust and reduce the slump flow effect. The 3D printing shape with low impact of twisting the clay. Usually, we use the kiln to dry clay to increase the hardness system. The drying method strengthens the 3D ceramic shape. After the 3D printer finishes printing the form, they take it out and place it in a drying microwave for exposed to $1000^{\circ}$ for $1 \mathrm{~h}$ after being dried for one day at lab temperature. We chose a microwave oven drying the 3D printed shape as a solution to be affordable and allow students to use it in their lab. They ensured that all 3D forms did precisely before putting them inside the oven. If the 3D model does not make it exactly, do not dry it. One of the benefits of clay is that it can reprocess the material from failed prints.

According to British standards, we test the compressive strength for all 3D printed ceramic shapes (Pentagon, Rectangular, and circular) after the drying process, as shown in Fig. 11. We are using the compressed under a uni-axial load (the ADR-Auto V2.0 Range machine) to test the 3D printed ceramic samples, as shown in Fig. 12a, b, respectively before and after the test.

The product cracks and the shell and core parts are detached at estimated compressive stress of $9.6 \mathrm{~N} / \mathrm{mm}^{2}$ for the pentagon and $8.6 \mathrm{~N} / \mathrm{mm}^{2}$ for a circular shape, as shown in Table 3.

Table 3 summarizes the relationship between the process of making 3D printed clay, the composition of the clay,

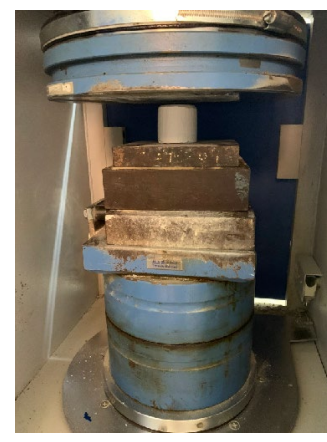

(a) Sample during the squeezing test

Fig. 12 Crushing strengths and the optimization of the printing parameters. However, the strength can increase through the hardness material, which improves the paste stability and reduces the shrinkage crack in the 3D printed samples. Figure 13 summarizes the strength of the 3D printed shapes depending on the wall thickness, which means that the nozzle's size is essential to get a 3D printed form with high strength. Results also showed that we wall thickness, which increased interlayer bond strength up to $10 \%$ compared to low wall thickness specimens.

\section{Discussion}

The analysis of the results of the study are summarized as follows:

- The successful result is associated with a decrease in the viscosity of the material $(\mathrm{W} / \mathrm{C}=0.65)$, low printing speed $(24 \mathrm{~mm} / \mathrm{s})$, and proper material flow $(1 \mathrm{~mm} / \mathrm{s})$.

- Before slicing, we need to consider the nozzle's size and the corresponding layer height. The orifice is one of the most important parameters of the 3D printing ceramic (3 mm nozzle).

- All clays can be used for 3D printing, but some clays with high performance are better than others. We

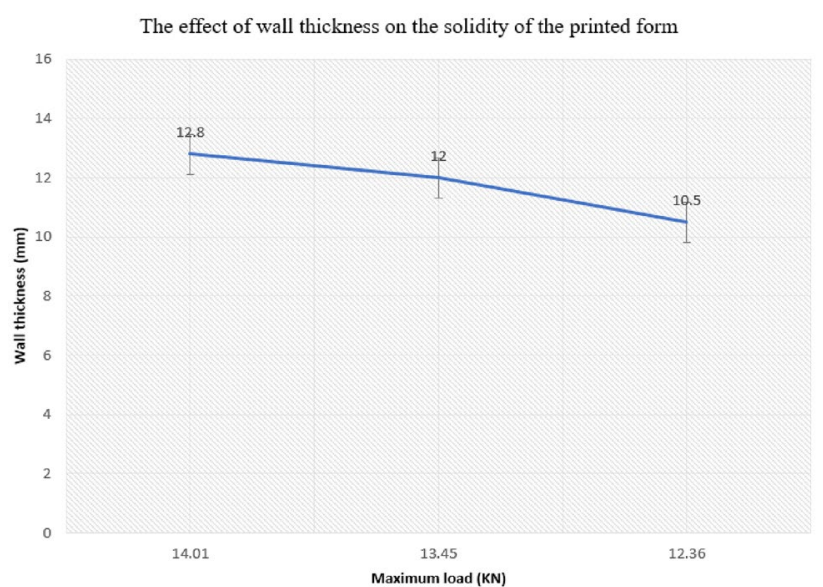

Fig. 13 The effect of the wall thickness on the solidity of the printed shape
Table 3 Hardened performance characteristics of the $3 \mathrm{D}$ printing samples

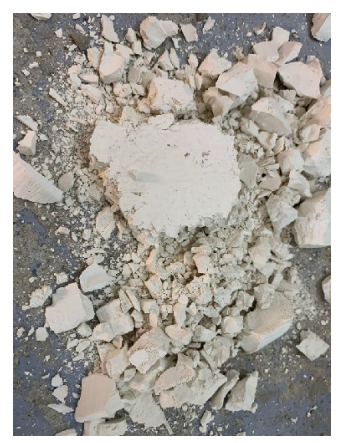

(b) After compression test

\begin{tabular}{llll}
\hline Sample shape & Pentagon & Rectangular shape & Circular shape \\
Wall thickness & $12.8 \mathrm{~mm}$ & $10.5 \mathrm{~mm}$ & $12 \mathrm{~mm}$ \\
Calculated face area & $1462.5 \mathrm{~mm}^{2}$ & $4173.9 \mathrm{~mm}^{2}$ & $6792.3 \mathrm{~mm}^{2}$ \\
Pace rate & $2.4 \mathrm{KN} / \mathrm{s}$ & $2.2 \mathrm{KN} / \mathrm{s}$ & $2.13 \mathrm{KN} / \mathrm{s}$ \\
Maximum load & $14.01 \mathrm{KN}$ & $12.36 \mathrm{KN}$ & $13.45 \mathrm{KN}$ \\
Estimated compressive Str & $9.6 \mathrm{~N} / \mathrm{mm}^{2}$ & $7.3 \mathrm{~N} / \mathrm{mm}^{2}$ & $8.6 \mathrm{~N} / \mathrm{mm}^{2}$ \\
\hline
\end{tabular}


choose the less sticky clay that has a good texture and dries quickly.

- We use the Archimedes screw print head (WASP), so we do not use clay that is too rough. Otherwise, the print head will be damaged.

- The dispensing system included the pneumatic plunger with an Archimedes screw extruder, which provided better flow and continuous extrusion of clay. Simultaneously, it was hard to control the layering of clay by only the air pressure system (single step).

- The air compressor forces the clay through the container, finally extruding through the nozzle. The optimal air pressure is $86 \mathrm{PSI}$.

\section{Conclusion}

This research aims to study the ability of 3D printing technology to implement the volumetric designs for ceramics using two steps of the dispersed FDM 3D printer into a prototype ceramic printer for the slurry suspension extrusion process. This work presents the conversion of an existing FDM printer to a 3D ceramic printer. This work created several 3D printer prototypes using clay materials after determining the best specifications in terms of the water-to-clay ratio of the 3D printer $(W / C=0.6)$. The search for an optimal formation for constructing ceramic shapes that meet the basic requirements of direct printing technology is the answer to several essential defects of this construction method, such as material viscosity, material properties, nozzle size, and printing speed. 3D printers are changing the philosophy of making pottery dielectric or ceramic shapes. Specifically, More work is needed in making clay pottery, as there are many sensors and patch antennas ranging from dielectric to ceramic. Actual printing time and cost may vary. In the future, we will install a drying system with the equipment to improve the printer's yield. Converting the FDM 3D printer to a LDM 3D printer is applicable and cheap with satisfying results to be used in a research lab for an antenna designed with clay R\&D.

Acknowledgements First and foremost, praises and thanks are due to God, the Almighty, for His showers of blessings throughout this research work. The authors want to express their deep and sincere gratitude to their team.

\section{Declarations}

Conflict of interest The authors declare that they have no conflict of interest.
Open Access This article is licensed under a Creative Commons Attribution 4.0 International License, which permits use, sharing, adaptation, distribution and reproduction in any medium or format, as long as you give appropriate credit to the original author(s) and the source, provide a link to the Creative Commons licence, and indicate if changes were made. The images or other third party material in this article are included in the article's Creative Commons licence, unless indicated otherwise in a credit line to the material. If material is not included in the article's Creative Commons licence and your intended use is not permitted by statutory regulation or exceeds the permitted use, you will need to obtain permission directly from the copyright holder. To view a copy of this licence, visit http://creativecommons. org/licenses/by/4.0/.

\section{References}

1. Tena MPG, Gilabert J, Montolio J, Corrales J, Julia Toledo M, Rosa Pérez M (2016) 3D printing of ceramic pieces by extruding clay suspensions. Unpublished. https://doi.org/10.13140/ RG.2.1.3885.8005

2. Faksawat K, Limsuwan $P$, Naemchanthara K (2021) 3D printing technique of specific bone shape based on raw clay using hydroxyapatite as an additive material. Appl Clay Sci. https:// doi.org/10.1016/j.clay.2021.106269

3. Huang Y, Leu MC, Mazumder J, Donmez A (2015) Additive manufacturing: current state, future potential, gaps and needs, and recommendations. J Manuf Sci Eng. https://doi. org/10.1115/1.4028725

4. Harikrishnan U, Soundarapandian S (2018) Fused deposition modelling based printing of full complement bearings. Procedia Manuf 26:818-825. https://doi.org/10.1016/j.promfg.2018. 07.102

5. McDonald L (2019) 3D printed ceramics. https://ceramics.org/ tag/3d-printed-ceramics

6. Singh J, Chawla K, Singh R (2020) Applications of thermoplastic polymers in 3D printing. In: Reference module in materials science and materials engineering. Elsevier. https://doi.org/ 10.1016/b978-0-12-820352-1.00010-9

7. Schmitt BM, Zirbes CF, Bonin C, Lohmann D, Lencina DC, da Costa Sabino Netto A (2018) A comparative study of cartesian and delta 3D printers on producing PLA parts. Mater Res 20(2):883-886. https://doi.org/10.1590/ 1980-5373-mr-2016-1039

8. Ngo TD, Kashani A, Imbalzano G, Nguyen KTQ, Hui D (2018) Additive manufacturing (3D printing): a review of materials, methods, applications and challenges. Compos B Eng 143:172196. https://doi.org/10.1016/j.compositesb.2018.02.012

9. Zhang D, Jonhson W, Herng TS, Ang YQ, Yang L, Tan SC, Peng E, He H, Ding J (2020) A 3D-printing method of fabrication for metals, ceramics, and multi-materials using a universal selfcurable technique for robocasting. Mater Horiz 7(4):10831090. https://doi.org/10.1039/c9mh01690b

10. Gojzewski H, Guo Z, Grzelachowska W, Ridwan MG, Hempenius MA, Grijpma DW, Vancso GJ (2020) Layer-by-layer printing of photopolymers in 3D: how weak is the interface? ACS Appl Mater Interfaces 12(7):8908-8914. https://doi.org/10.1021/ acsami.9b22272

11. Farzadi A, Solati-Hashjin M, Asadi-Eydivand M, Osman NAA (2014) Effect of layer thickness and printing orientation on mechanical properties and dimensional accuracy of 3D printed porous samples for bone tissue engineering. PLoS ONE. https://doi.org/10.1371/journal.pone.0108252 
12. Zhong F, Liu W, Zhou Y, Yan X, Wan Y, Lu L (2020) Ceramic 3D printed sweeping surfaces. Comput Graph 90:108-115. https://doi.org/10.1016/j.cag.2020.05.007

13. O'Shea I (2017) Clay 3D printing with Jonathan keep.... http:// ivoroshea.blogspot.com/2017/04/clay-3d-printing-with-jonat han-keep.html

14. Zhang M, Yang L (2016) Ceramic product forming technologies research based on 3D printing. IEEE Access 4:9345-9349. https://doi.org/10.1109/access.2016.2642122

15. Segura-Cardenas E, Velasquez-Garcia LF (2020) Additively manufactured robust microfluidics via silver clay extrusion. J Microelectromech Syst 29(3):427-437. https://doi.org/10. 1109/jmems.2020.2982559

16. Kristiawan RB, Imaduddin F, Ariawan D, UbaidillahArifin Z (2021) A review on the fused deposition modeling (FDM) 3D printing: filament processing, materials, and printing parameters. Open Eng 11(1):639-649. https://doi.org/10.1515/eng-2021-0063

17. Vialva $T$ (2019) University of Delaware researchers develop $5 \mathrm{G}$ antennas with Xjet Carmel 1400 3D printer

18. Heidari-Rarani M, Rafiee-Afarani M, Zahedi AM (2019) Mechanical characterization of FDM 3D printing of continuous carbon fiber reinforced PLA composites. Compos B Eng 175:107-147. https://doi.org/10.1016/j.compositesb.2019.107147

19. Mazingue G, Romier M, Capet N (2021) 3D printed ceramic lowprofile GNSS Antenna for SmallSats. In: 50th European microwave conference (EuMC). IEEE. https://doi.org/10.23919/eumc4 8046.2021.9337981

20. Mazingue G, Byrne B, Romier M, Capet N (2020) 3D printed ceramic antennas for space applications. In: 14th European conference on antennas and propagation (EuCAP). IEEE. https://doi. org/10.23919/eucap48036.2020.9135312

21. Mahouti M, Kuskonmaz N, Mahouti P, Belen MA, Palandoken M (2020) Artificial neural network application for novel 3D printed nonuniform ceramic reflectarray antenna. Int J Numer Model. https://doi.org/10.1002/jnm.2746

22. Helena D, Ramos A, Varum T, Matos JN (2021) The use of 3D printing technology for manufacturing metal antennas in the 5G/loT context. MDPI Sens 21(10):3321. https://doi.org/10.3390/ s21103321

23. Dommati H, Ray SS, Wang J-C, Chen S-S (2019) A comprehensive review of recent developments in 3D printing technique for ceramic membrane fabrication for water purification. RSC Adv 9(29):16869-16883. https://doi.org/10.1039/c9ra00872a

24. Prathumwan R, Subannajui K (2020) Fabrication of a ceramic/ metal (Al2O3/AI) composite by 3D printing as an advanced refractory with enhanced electrical conductivity. RSC Adv 10(54):32301-32308. https://doi.org/10.1039/d0ra01515f

25. Hager I, Golonka A, Putanowicz R (2016) 3D printing of buildings and building components as the future of sustainable construction? Procedia Eng 151:292-299. https://doi.org/10.1016/j. proeng.2016.07.357
26. Savage D, Liu J (2015) Water/clay ratio, clay porosity models and impacts upon clay transformations. Appl Clay Sci 116-117:1622. https://doi.org/10.1016/j.clay.2015.08.011

27. Horpibulsuk S, Miura N, Nagaraj TS (2005) Clay-water-cement ratio identity for cement admixed soft clays. J Geotech Geoenviron Eng 131(2):187-192. https://doi.org/10.1061/(asce)10900241(2005)131:2(187)

28. Valkenaers H, Vogeler F, Ferraris E, Voet A, Kruth J-P (2013) A novel approach to additive manufacturing: screw extrusion 3D-printing. In: 10th international conference on multi-material micro manufacture. Research Publishing Services. https://doi. org/10.3850/978-981-07-7247-5-359

29. Keep J (2013) Make your own clay auger printhead with mechanical RAM delivery. http://www.keep-art.co.uk/printhead. html

30. Manikandan K, Jiang X, Singh AA, Li B, Qin H (2020) Effects of nozzle geometries on 3D printing of clay constructs: quantifying contour deviation and mechanical properties. Procedia Manuf 48:678-683. https://doi.org/10.1016/j.promfg.2020.05.160

31. Matúš M, Šooš L', Križan P, Beniak J, Ondruška J (2015) Design theory for screw geometry in a briquette press. Manuf Technol 15(3):384-391. https://doi.org/10.21062/ujep/x.2015/a/12132489/mt/15/3/384

32. Matúš M, Beniak J, Križan P, Šooš L' (2020) Mathematical design theory of screw extruder used for additive manufacturing. Glob J Eng Technol Adv 5(3):059-068. https://doi.org/10.30574/gjeta. 2020.5.3.0113

33. Gordeev EG, Galushko AS, Ananikov VP (2018) Improvement of quality of 3D printed objects by elimination of microscopic structural defects in fused deposition modeling. PLoS ONE 13(6):1-19. https://doi.org/10.1371/journal.pone.0198370

34. Baumann F, Bugdayci H, Grunert J, Keller F, Roller D (2015) Influence of slicing tools on quality of 3D printed parts. Comput Aided Des Appl 13(1):14-31. https://doi.org/10.1080/16864360. 2015.1059184

35. Guo C, Zhang M, Bhandari B (2019) Model building and slicing in food 3D printing processes: a review. Compr Rev Food Sci Food Saf 18(4):1052-1069. https://doi.org/10.1111/1541-4337.12443

36. Kratochvíl J, Sadílek M, Musil V, Pagáč M, Stančeková D (2018) The effectiveness of strategies printing printer easy 3D maker. Adv Sci Technol Res J 12(2):197-205. https://doi.org/10.12913/ 22998624/91890

Publisher's Note Springer Nature remains neutral with regard to jurisdictional claims in published maps and institutional affiliations. 